\title{
Chronic disease self-management and exercise in COPD as pulmonary rehabilitation: a randomized controlled trial
}

This article was published in the following Dove Press journal:

International Journal of COPD

19 May 2014

Number of times this article has been viewed

\author{
Helen L Cameron-Tucker' \\ Richard Wood-Baker ${ }^{1}$ \\ Christine Owen ${ }^{2}$ \\ Lyn Joseph ${ }^{3}$ \\ E Haydn Walters' \\ 'Centre of Research Excellence for \\ Chronic Respiratory Disease and \\ Lung Aging, School of Medicine, \\ University of Tasmania, Hobart, TAS, \\ Australia; ${ }^{2}$ Faculty of Education, \\ University of Tasmania, Hobart, TAS, \\ Australia; ${ }^{3}$ Department of Respiratory \\ Medicine, Royal Hobart Hospital, \\ Hobart, TAS, Australia
}

Correspondence: Helen L Cameron-

Tucker

School of Medicine, University of Tasmania, Medical Science I Building, Private Bag 23, Hobart, TAS 7000, Australia

$\mathrm{Tel}+61362264893$

Fax +6I 362267704

Email cameronh@utas.edu.au
Purpose: Both exercise and self-management are advocated in pulmonary rehabilitation for people with chronic obstructive pulmonary disease (COPD). The widely used 6-week, groupbased Chronic Disease Self-Management Program (CDSMP) increases self-reported exercise, despite supervised exercise not being a program component. This has been little explored in COPD. Whether adding supervised exercise to the CDSMP would add benefit is unknown. We investigated the CDSMP in COPD, with and without a formal supervised exercise component, to address this question.

Patients and methods: Adult outpatients with COPD were randomized to the CDSMP with or without one hour of weekly supervised exercise over 6 weeks. The primary outcome measure was 6-minute walk test distance (6MWD). Secondary outcomes included self-reported exercise, exercise stage of change, exercise self-efficacy, breathlessness, quality of life, and self-management behaviors. Within- and between-group differences were analyzed on an intention-to-treat basis.

Results: Of 84 subjects recruited, 15 withdrew. 6MWD increased similarly in both groups: CDSMP-plus-exercise (intervention group) by $18.6 \pm 46.2 \mathrm{~m}$; CDSMP-alone (control group) by $20.0 \pm 46.2 \mathrm{~m}$. There was no significant difference for any secondary outcome.

Conclusion: The CDSMP produced à small statistically significant increase in 6MWD. The addition of a single supervised exercise session did not further increase exercise capacity. Our findings confirm the efficacy of a behaviorally based intervention in COPD, but this would seem to be less than expected from conventional exercise-based pulmonary rehabilitation, raising the question of how, if at all, the small gains observed in this study may be augmented.

Keywords: supervised exercise, physical capacity, 6-minute walk distance

\section{Introduction}

Developing self-management skills is now seen as a standard component of pulmonary rehabilitation (PR) programs. ${ }^{1-3}$ Indeed, PR is considered an integral component of managing chronic obstructive pulmonary disease (COPD), a progressive disabling respiratory and systemic condition. ${ }^{4}$ Guidelines also recommend that PR should include a detailed assessment, exercise, education, and psychosocial support. ${ }^{1,2}$

Exercise in PR has demonstrated improvements in physical capacity, healthrelated quality of life, dyspnea, and fatigue. ${ }^{5}$ Recommendations have stipulated at least three exercise sessions weekly, two of which are to be preferably supervised. ${ }^{6}$ However, the supporting evidence for this degree of supervised exercise is limited ${ }^{7}$ and was subsequently contradicted by others who provided only once-weekly exercise supervision. $^{8-11}$ These later studies question the conventionally recommended degree 
of exercise supervision. The frequency of supervised exercise sessions has relevance to our study. As we will explain in the Materials and methods section, our intervention was once-weekly supervised exercise added to a self-management program, which we offered as a combined PR approach.

Condition-specific education in PR has traditionally been delivered in a didactic format and has not demonstrated additional benefit in terms of physical or exercise capacity. ${ }^{2,12-14}$ Consequently, exercise, not education, has become the cornerstone of PR. However, the benefits of the traditional format for PR, especially on physical capacity and exercise behavior, wane over time..$^{15,16}$ This has led to an emphasis on behavioral strategies in PR as a potential means of maintaining the acute gains, ${ }^{3,16}$ but this is little tested.

Indeed, self-management interventions, underpinned by health psychology principles, have been seen as an alternative to the conventional PR approach. Such programs are seen particularly as strategies for improving health behaviors, such as regular exercise, and integrating them into daily life. Chronic disease self-management is defined as a process that facilitates an individual's confidence and capability to engage in health-promoting behaviors in order to deal with the impact of their condition on all aspects of their health - namely, a sense of self, physical, emotional, social, and medical domains so as to maximize function and quality of life. ${ }^{17,18}$ Self-management education or training is recognized as needing to be interactive, to facilitate not only the acquisition of health behavior knowledge but its implementation, by fostering the self-management skills of collaborative goal-setting with associated action plans, problem solving, and decision-making. ${ }^{13}$ However, with the exception of increased uptake of a symptom-based action plan to manage COPD exacerbations (ie, self-management of symptoms ), ${ }^{19}$ and some decrease in hospitalization rates, ${ }^{20}$ the evidence for the efficacy of holistic COPD-specific selfmanagement approaches, while popular and continuing to increase in practice, has been limited. ${ }^{20-25}$

However, in more general chronic disease situations, statistically sustained significant improvements in health care utilization, health status, and health behaviors such as self-reported exercise have been reported for participants who attended the Stanford Chronic Disease Self-Management Program (CDSMP). ${ }^{26}$ The CDSMP, either provided at a medical center or community-based, is a generic, 6-week, group-based self-management education approach led by two trained leaders. ${ }^{26}$ Such benefits were subsequently supported in a review of self-management approaches ${ }^{27}$ and have been widely implemented, as indeed is the case in our institution. The CDSMP includes educational information delivered in a lecturette style and supplemented by a companion book. The topics cover generic health information, the basis of which is comparable to that relating to health behaviors in conventional PR (Table 1). Some condition-specific information is included in the companion book. The interactive format of the CDSMP deliberately fosters self-efficacy ("confidence") to manage one's health condition through mastery (practicing skills through setting action plans), vicarious experiences (role modelling and peer support), social persuasion

Table I Comparison of program content

\begin{tabular}{|c|c|}
\hline CDSMP program content & $\begin{array}{l}\text { PR program content (Team member delivering the } \\
\text { lecture) }\end{array}$ \\
\hline Condition-specific information in the companion book & $\begin{array}{l}\text { Heart and lungs: structure and function in relation to chronic } \\
\text { heart and lung conditions (physiotherapist) }\end{array}$ \\
\hline Symptom management: shortness of breath, breathing exercises & $\begin{array}{l}\text { Monitoring and responding to symptoms: relaxation, breathing } \\
\text { exercises, managing breathlessness }\end{array}$ \\
\hline \multicolumn{2}{|l|}{ Muscle relaxation } \\
\hline Endurance exercise (discussion) & Beginning an exercise program (physiotherapist) \\
\hline \multicolumn{2}{|l|}{ Cognitive symptom management } \\
\hline $\begin{array}{l}\text { Symptom management: anger, fear, frustration, depression, } \\
\text { fatigue, pain }\end{array}$ & $\begin{array}{l}\text { Living with heart and lung conditions: emotional and social impact, } \\
\text { communication (social worker) }\end{array}$ \\
\hline \multicolumn{2}{|l|}{ Communication skills } \\
\hline \multicolumn{2}{|l|}{ Advance directives for health care } \\
\hline \multicolumn{2}{|l|}{ Working with and informing the health care team } \\
\hline Medication usage: generic advice, specific information in companion book & Medications and delivery devices: condition-specific (pharmacist) \\
\hline Healthy eating & Nutrition (dietician) \\
\hline Specific suggestions in the companion book & Activity modification (occupational therapist) \\
\hline How to set action plans and problem solve & Not formally addressed \\
\hline
\end{tabular}

Notes: I) The CDSMP course content is presented in comparison with PR and not as the content of the six individual CDSMP sessions. PR is shown as presented in the six sessions with the presenting health professional at our center. 2) Supervised exercise preceded the educational component of PR. The CDSMP has no supervised exercise component. Abbreviations: CDSMP, Chronic Disease Self-Management Program; PR, pulmonary rehabilitation. 
(encouragement via guided feedback), and reinterpretation of symptoms (exploring different explanations of symptoms) ${ }^{28}$ Unlike PR, the CDSMP is not designed to include supervised exercise, yet has been reported to increase self-reported exercise $^{26,29}$ and decrease dyspnea. ${ }^{29}$ Any added benefit of formally adding supervised exercise to the CDSMP has not been reported, especially in COPD.

Thus, with an increasing worldwide focus on self-management of chronic conditions, the opinion of hospital management at our institution was that the rehabilitation needs of the target population might be most effectively met through the CDSMP rather than conventional PR. A small pilot of the CDSMP for people with COPD compared with our traditional $\mathrm{PR}^{30}$ found that the CDSMP alone improved physical capacity by $30 \mathrm{~m}$, measured by the 6-minute walk distance (6MWD). ${ }^{31}$ However, with supervised exercise considered an essential component of PR and the benefits of such exercise for people with COPD established, ${ }^{5}$ we felt that it was incumbent on us to investigate more fully the likely benefits of the CDSMP approach on exercise capacity, specifically in COPD patients, as well as on more subjective endpoints in this context. We wished to establish whether supervised exercise in addition to the CDSMP would have added benefit compared with the CDSMP alone. This would be a step to informing us of whether the CDSMP with supervised exercise, or without, might offer an alternative to more traditional PR.

\section{Materials and methods}

\section{Study design}

This was a parallel group, randomized clinical trial aiming to investigate both the efficacy of the CDSMP itself in COPD and, more particularly, the addition of supervised exercise to the CDSMP on physical capacity measured by the 6MWD. The trial was registered with the Australian and New Zealand Clinical Trials Registry (ACTRN12610000781044).

In our pilot study already mentioned, which had included a similar population of people with COPD, we found the mean baseline 6MWD to be $365 \mathrm{~m}$, with a standard deviation of $74 \mathrm{~m} \cdot{ }^{30}$ The acknowledged minimal clinical important difference (MCID) at that time was reported as $54 \mathrm{~m} .{ }^{32}$ To achieve this difference in exercise capacity, for power of 0.8 and level of significance of 0.05 , using a two-sided $t$-test for our primary outcome of $6 \mathrm{MWD}$, we calculated that the current study would require 31 participants in each arm to allow demonstration of superiority for the active intervention by this amount. Allowing for the $25 \%$ dropout rate seen in the pilot, we estimated a total of 78 participants needed to be recruited, with 1:1 randomization to the exercise intervention arm of the CDSMP plus a single supervised exercise session versus the CDSMP alone.

Randomization used a random numbers table with allocation stored in opaque sealed envelopes until completion of baseline data measurement. Participants were assigned a depersonalized identification number, to provide blinding during data analyses. However, a double-blind clinical trial was not possible, as there was no appropriate dummy for the exercise component, and the whole population attended the CDSMP together.

\section{Study subjects}

Participants were recruited from patients referred by clinicians to PR at the Royal Hobart Hospital, a tertiary, university-affiliated, public hospital. Participants gave written informed consent. Ethical approval was granted by the Tasmanian Human Research Ethics Committee (H0008105).

Referring staff were aware that our rehabilitation service was intending to trial the addition of formal exercise to the CDSMP. Inclusion criteria included being over age 18 years, agreeable to attend supervised exercise as well as the CDSMP as randomized, a firm diagnosis of COPD, and there being at least 2 months since an acute exacerbation. Exclusion criteria were cognitive impairment, inability to provide informed consent or complete a self-administered questionnaire, previous CDSMP or PR attendance within the past 2 years, and standard contraindications to exercise. ${ }^{33}$

\section{Detail of interventions}

The intervention group underwent 6 weeks of a 1-hour, weekly, supervised group exercise session of aerobic and strengthening exercises for upper and lower limbs, individualized for each participant, in the same week as the 6-week CDSMP. We were able to offer only this 1-hour supervised exercise session per week due to operational constraints. However, this approach has been supported by others. ${ }^{8,11}$ Participants were offered a choice of attending the supervised exercise session either in the morning prior to the CDSMP or later in the week. The first exercise session took place in the week of the first CDSMP session. In collaboration with the physiotherapist-investigator, an individualized exercise regime was determined with each participant. A physiotherapy assistant trained in exercise supervision and not otherwise involved in the study supervised the actual exercise sessions, with the physiotherapist available for consultation if needed. Exercise intensity in the intervention group was determined by using the modified Borg Rating of Perceived 
Exertion (RPE) Scale $(0-10 ; 10=$ maximum $) .{ }^{34}$ A minimum of moderate intensity $(\mathrm{RPE}=3)$ exercise was aimed for, according to recommended exercise guidelines, ${ }^{35}$ and a maximum intensity of strong (RPE $=5$ ).

As it was not possible for us to offer separate CDSMP sessions for intervention and control participants, they attended the CDSMP together, each receiving the same encouragement and information about following a home exercise regime. To avoid contamination, the intervention group was requested not to discuss experience of supervised exercise with controls. Controls, receiving the CDSMP alone, were offered supervised exercise on completion of their study participation.

The participants attended the 6-week group-based CDSMP, with sessions of 2.5 hours duration offered once per week, facilitated by the respiratory nurse and the physiotherapist-investigator who had both undertaken leader training. The sessions were interactive with lecturettes, problem solving, brain storming, action planning, and reportingback activities. There were up to 12 participants per cohort. A comparison of the CDSMP lecturette topics with those previously delivered in PR education is shown in Table 1.

\section{Outcome measures and data analyses}

Outcomes were assessed in the week prior to and the week following completion of the interventions. It was deemed more ethical to first determine whether or not a significant and clinically meaningful change resulted for the intervention in the short-term before extending the study to longer-term follow-up.

The primary outcome was physical capacity measured by the $6 \mathrm{MWD}^{31}$ and was assessed by an assistant not connected with the trial, affording some degree of objectivity at that point. Secondary outcomes, more directed to the likely efficacy outcomes of the CDSMP, are detailed in Table 2. ${ }^{31,35-41}$ We selected the Short-Form 36 Questionnaire, version 2 (SF36) as the quality-of-life measure to account for the impact of comorbidities. It has been deemed as responsive as the COPD-specific Saint George's Respiratory Questionnaire ${ }^{42}$ at detecting even small changes in people with COPD. ${ }^{43}$

Data were analyzed on an intention-to-treat basis, using the statistical software package SPSS (SPSS, Chicago, IL, USA), version 15. The data analyst was blinded to participant allocation until all analyses were completed. Missing variables were replaced by carrying forward the last item measured, and for missing cases, the baseline data was carried forward to the post-data. The exception was for the CHAMPS (Community Healthy Activities Model Program for Seniors) self-report of physical activity, whereby all missing data were scored as zero. ${ }^{39}$

Results are reported as medians with ranges or means with standard deviations, depending on distribution of data points. Differences in outcomes were compared using Student's $t$-tests for parametric data and Mann-Whitney $U$ tests for nonparametric data. Differences in proportions were tested using chi-squared tests. Significance for the primary outcome was set at a $P$-value $<0.05$. Due to the large number of secondary outcomes, significance levels for these were calculated using a highly conservative Bonferroni correction $(P<0.003){ }^{44}$

\section{Results}

\section{Participants}

There were 316 potential participants referred for PR (Figure 1), with similar proportions from the private sector (30\%), public inpatient service (32\%), and public outpatient clinics (35\%). The referral source was not recorded in $3 \%$. Overall, attendance at screening was $70 \%(n=221)$. Of those not screened, the majority declined an appointment, while many others failed to keep their appointment (Figure 1). Those referred from the hospital wards were least likely, whereas those referred from the private sector were most likely, to attend a screening appointment $(P<0.001)$. Of those deemed eligible at screening visit, $21 \%$ refused further involvement. Participants attended a median of five sessions of the CDSMP, and where appropriate, of the supervised exercise sessions.

There were 15 withdrawals (five intervention and ten controls) due to illness, family issues, or medical appointments. Data were missing for four participants: one could not cooperate, feeling "overwhelmed" by the process and subsequently withdrew permission for their data to be used; one could not complete the baseline walking test due to increasing breathlessness, and for two, baseline questionnaires were misplaced.

Participant characteristics are depicted in Table 3. The groups did not differ significantly in any baseline demographic measure. Outcome variables at baseline were similar, with no statistically significant differences between groups (Table 4). The 15 withdrawals had no baseline differences compared with completers, defined as those attending at least one CDSMP session and both data collections.

\section{Primary outcome}

There were statistically significant increases in 6MWD in both groups, of around $20 \mathrm{~m}$ on average (Table 5). However, there 

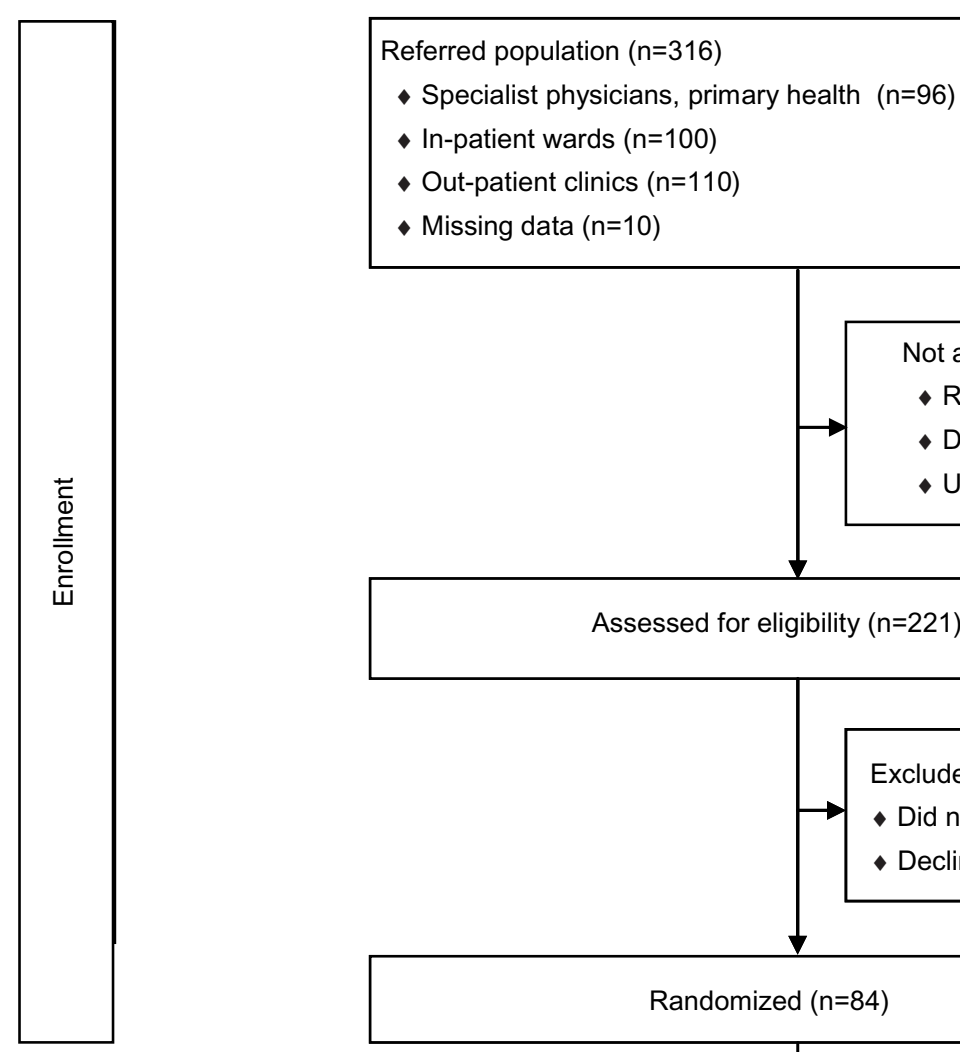

Referred population $(n=316)$

- Specialist physicians, primary health $(n=96)$

- In-patient wards $(n=100)$

- Missing data $(n=10)$

Not assessed for eligibility $(n=95)$

- Refused appointment $(n=60)$

- Did not keep appointment $(n=31)$

- Unable to contact $(n=4)$

Assessed for eligibility $(n=221)$
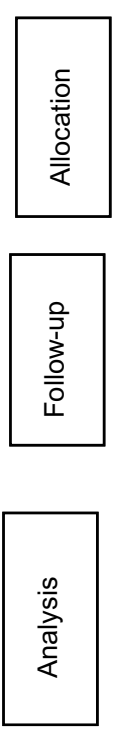

.

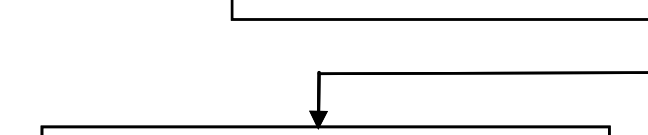

Allocated to intervention $(n=43)$

Withdrew $(n=5)$

- Unwell $(n=3)$

- Other $(n=2)$
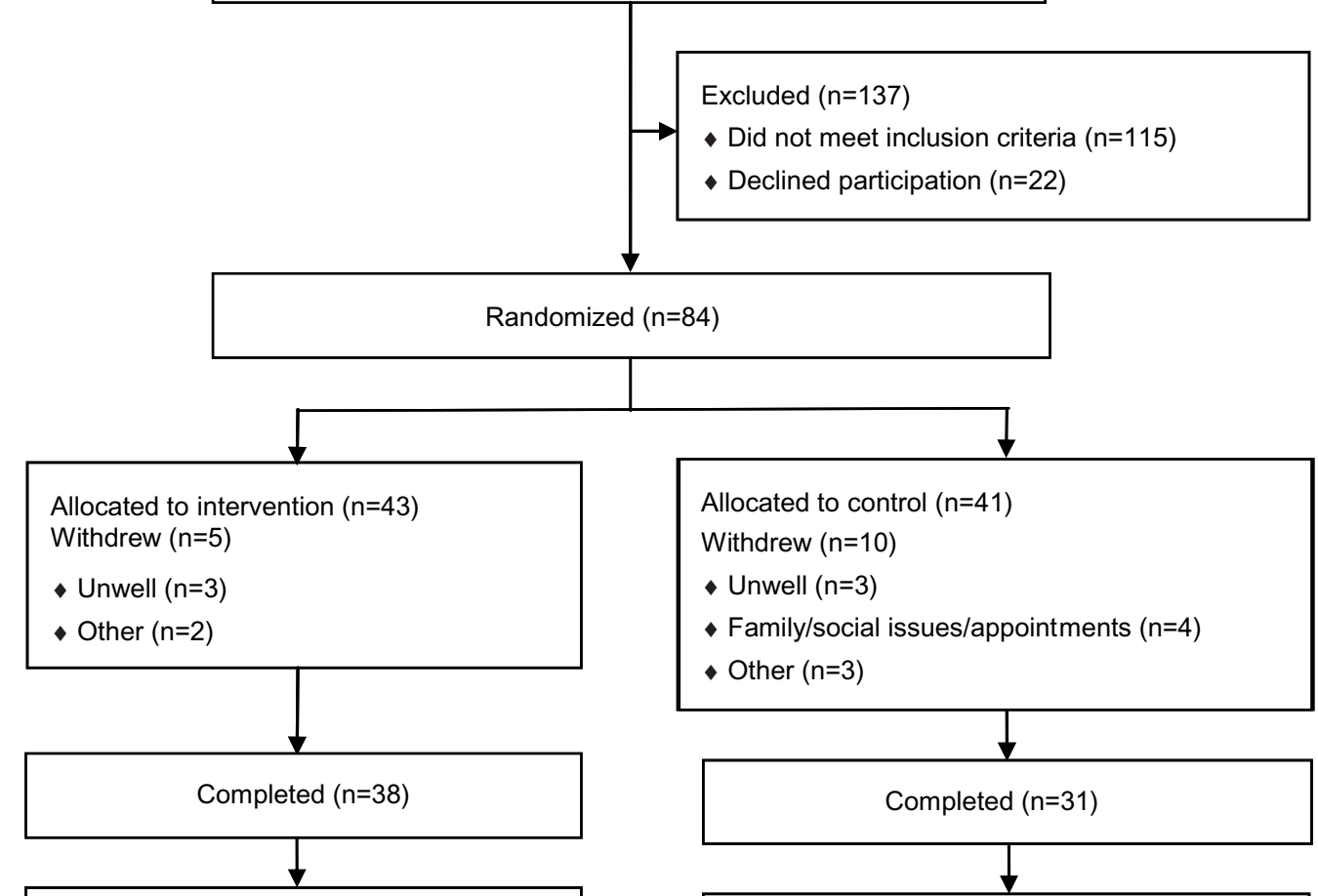

Analyzed intention-to-treat: (6MWD n=42; questionnaires $n=41$ )

- Excluded from analysis (missing data: case missing $n=1$; baseline questionnaires misplaced $n=1$ )

Figure I Flowchart showing participant's progress through the study. Abbreviation: 6MWD, 6-minute walk test distance.

was no statistically significant difference between the groups. The number of participants in each group who reached the MCID of $54 \mathrm{~m}$ was similar, $22 \%$ in the CDSMP-plus-exercise group and $23 \%$ in the CDSMP-only group.

The associations between the changes in 6MWT distance and the selected variables of age, sex, education, breathlessness, exercise duration, and frequency, SF-36 physical and mental component summaries, exercise self-efficacy, and body mass index were weak; all Pearson's correlation coefficients were less than 0.3 , and none reached statistical significance. Severity and frequency of breathlessness were selected rather than COPD grade, as the latter had missing data. The strongest correlations with the change in 6MWD were frequency of moderate exercise $(r=-0.188, P=0.066)$, and exercise self-efficacy $(r=0.140$, 
Table 2 Outcomes and measures

\section{Primary outcome and measure}

Physical capacity, measured by the 6MWD, a field walking test ${ }^{31}$

Secondary outcomes and measures

\section{Outcome}

Self-reported exercise

Self-efficacy for exercise

Exercise participation criteria (achieving minimum

recommended level of daily exercise)

\section{Measure}

CHAMPS Activities Questionnaire for Older Adults ${ }^{39 *}$

Exercise: Self-Efficacy measure ${ }^{37 *}$

Achieving weekly exercise $\mathrm{e}^{35,36}$

"Regular Exercise is any planned physical activity (eg, brisk walking, aerobics, bicycling, swimming, line-dancing, tennis, doing formal exercises etc.) performed to increase or maintain health and physical fitness. Such exercise should be performed on all or at least 5 days of the week to accumulate 30 minutes or more per day. Exercise does not have to be painful to be effective but should be done at a moderate level that increases your breathing rate and makes you feel warmer Do you exercise regularly according to the definition above? Yes/No"

Stage of change for exercise SOB

Self-management behaviors HRQoL
Exercise: Stages of Change - Short Form questionnaire ${ }^{36 *}$

$10 \mathrm{~cm}$ VAS $^{38}$

Flinders University PIH Scale ${ }^{40 *}$

SF-36v2 Generic Health Survey ${ }^{41 *}$

Note: *Permission obtained for instrument use.

Abbreviations: 6MWD, 6-minute walk test distance; CHAMPS, Community Healthy Activities Model Program for Seniors; HRQoL, health-related quality of life; PIH, Partners in Health; SF-36v2, Short Form 36 version 2; SOB, shortness of breath; VAS, visual analog scale.

$P=0.132$ ), although neither were statistically significant. When entered in a multivariable linear regression model, the frequency of moderate exercise $(\beta=-0.257, P=0.048)$ and exercise selfefficacy $(\beta=0.220, P=0.089)$ explained only $7.9 \%$ of the variance in the change in 6MWD.

\section{Secondary outcomes}

Both groups increased similarly in the frequency of moderate exercise, achieving 3 days per week, and showed small increases in physical function, "role physical", and exercise self-efficacy ("confidence" to exercise), but none of these intragroup changes reached statistical significance. There were no statistically significant differences between the groups in these changes for any secondary outcome measure (Table 5). However, only the intervention group had a statistically significant increase, but only of 1 hour per week, in the duration of moderate intensity self-reported exercise $(P=0.002)$.

Table 3 Participant characteristics

\begin{tabular}{|c|c|c|c|c|}
\hline Variable & $\begin{array}{l}\text { Participants } \\
(n=84)\end{array}$ & $\begin{array}{l}\text { I: CDSMP + exercise } \\
(n=43)\end{array}$ & $\begin{array}{l}\text { C: CDSMP-only } \\
(n=4 I)\end{array}$ & $\begin{array}{l}P \text {-value } \\
\text { I versus C }\end{array}$ \\
\hline Female & 39 (46\%) & 20 (47\%) & 19 (46\%) & 0.99 \\
\hline Age, years & $65.8 \pm 9.35$ & $64.5 \pm 9.13$ & $67.1 \pm 9.4 I$ & 0.19 \\
\hline Married & $50(60 \%)$ & $25(58 \%)$ & $25(61 \%)$ & 0.97 \\
\hline Education: to year 8 & $21(26 \%)$ & $12(29 \%)$ & $9(23 \%)$ & 0.53 \\
\hline to year 10 & 37 (45\%) & $20(48 \%)$ & $17(43 \%)$ & \\
\hline to year 12 & $24(29 \%)$ & $10(24 \%)$ & $14(35 \%)$ & \\
\hline $\begin{array}{l}\text { Self-reported comorbidities: } \\
\text { present }\end{array}$ & $22(26 \%)$ & $9(21 \%)$ & $13(33 \%)$ & 0.35 \\
\hline $\begin{array}{l}\text { Referral source: primary } \\
\text { health or private practice }\end{array}$ & 37 (44\%) & $18(42 \%)$ & $19(46 \%)$ & 0.80 \\
\hline Public hospital wards & $19(23 \%)$ & II (26\%) & $8(20 \%)$ & \\
\hline Public outpatient clinics & $28(33 \%)$ & 14 (32\%) & $14(34 \%)$ & \\
\hline Socioeconomic status: & $43(54 \%)$ & 21 (53\%) & $22(55 \%)$ & 1.00 \\
\hline \multicolumn{5}{|l|}{ below State median } \\
\hline Body mass index, $\mathrm{kg} / \mathrm{m}^{2}$ & $29.0 \pm 7.07$ & $28.4 \pm 7.63$ & $29.7 \pm 6.50$ & 0.44 \\
\hline \multicolumn{5}{|l|}{ COPD severity: } \\
\hline Mild (60\%-80\%) & $20(29 \%)$ & $8(22 \%)$ & $12(38 \%)$ & 0.23 \\
\hline Moderate (40\%-59\%) & $16(23 \%)$ & II (30\%) & 5 (I5.6\%) & \\
\hline Severe $(<40 \%)$ & $33(48 \%)$ & $18(49 \%)$ & I5 (47\%) & \\
\hline
\end{tabular}

Notes: Data are reported as either raw number (percent) within study group status and as means \pm standard deviations. The $P$-values are from Student's $t$-tests or chi-squared analyses. Level of significance was set at $P<0.05$. COPD severity classified according to COPD-X Plan Australian and New Zealand management guidelines for COPD. ${ }^{50}$ Abbreviations: C, control; CDSMP, Chronic Disease Self-Management Program; COPD, chronic obstructive pulmonary disease; I, intervention. 
Table 4 Intervention versus control group: baseline outcome variables

\begin{tabular}{|c|c|c|c|}
\hline Variable & $\begin{array}{l}\text { Intervention } \\
\text { (CDSMP + exercise) }\end{array}$ & $\begin{array}{l}\text { Control } \\
\text { (CDSMP-only) }\end{array}$ & $P$-value \\
\hline Primary outcome & $(n=42)$ & $(n=40)$ & \\
\hline 6MWD, m & $351.6 \pm 122.9$ & $353.0 \pm 97.4$ & 0.953 \\
\hline Secondary outcomes & $(n=4 I)$ & $(n=40)$ & \\
\hline All exercise: duration, hours per week & $5.250(0.00-26.00)$ & $9.250(0.00-52.25)$ & 0.011 \\
\hline All exercise: frequency, times per week & $9.0(0.0-49.0)$ & $13.5(0.0-59.0)$ & 0.126 \\
\hline Moderate exercise: duration, hours & $0.500(0.00-19.50)$ & $1.500(0.00-10.25)$ & 0.171 \\
\hline Moderate exercise: frequency, times per week & $2.0(0.0-20.0)$ & $2.0(0.0-23.0)$ & 0.491 \\
\hline Exercise self-efficacy, scale $0-5$ & $2.7 \pm 1.1$ & $2.8 \pm 1.0$ & 0.763 \\
\hline Self-management behaviors, scale $0-8$ & $6.1 \pm 1.1$ & $6.2 \pm 1.0$ & 0.492 \\
\hline Shortness of breath: severity, cm & $7.1 \pm 2.3$ & $6.8 \pm 2.4$ & 0.592 \\
\hline Shortness of breath: frequency, $\mathrm{cm}$ & $6.9 \pm 2.6$ & $6.4 \pm 2.6$ & 0.330 \\
\hline SF-36v2 Physical Function & $29.26 \pm 8.99$ & $28.99 \pm 8.04$ & 0.886 \\
\hline SF-36v2 Role Physical & $31.95 \pm 10.37$ & $32.12 \pm 9.42$ & 0.938 \\
\hline SF-36v2 Bodily Pain & $45.64 \pm 11.68$ & $45.09 \pm 11.49$ & 0.832 \\
\hline SF-36v2 General Health & $30.30 \pm 9.88$ & $32.41 \pm 8.96$ & 0.317 \\
\hline SF-36v2 Vitality & $41.74 \pm 9.19$ & $40.77 \pm 9.69$ & 0.648 \\
\hline SF-36v2 Social Function & $42.75 \pm 13.19$ & $39.94 \pm 11.37$ & 0.309 \\
\hline SF-36v2 Role Emotional & $36.25 \pm 16.10$ & $37.22 \pm 15.28$ & 0.782 \\
\hline SF-36v2 Mental Health & $47.67 \pm 11.66$ & $46.21 \pm 10.68$ & 0.557 \\
\hline SF-36v2 Physical Component Summary & $31.53 \pm 8.19$ & $31.97 \pm 7.247$ & 0.796 \\
\hline SF-36v2 Mental Health Component Summary & $46.74 \pm 12.85$ & $45.53 \pm 12.17$ & 0.664 \\
\hline Achieving exercise criteria: Yes & II (26.8\%) & $6(15.0 \%)$ & 0.301 \\
\hline No & $30(73.2 \%)$ & $34(85.0 \%)$ & \\
\hline Stage of change for exercise: Precontemplation & $4(9.8 \%)$ & $6(15.0 \%)$ & 0.789 \\
\hline Contemplation & 14 (34.1\%) & 17 (42.5\%) & \\
\hline Preparation & $9(22.0 \%)$ & 7 (I7.5\%) & \\
\hline Action & $6(14.6 \%)$ & 5 (12.5\%) & \\
\hline Maintenance & 8 (19.5\%) & 5 (12.5\%) & \\
\hline
\end{tabular}

Notes: Data are reported as either raw number (percent) within study group, as mean \pm standard deviation, or as median with range. The $P$-values are from Student's $t$-tests, Mann-Whitney $U$ tests or chi-squared analyses, with level of significance $P<0.05$ for $6 \mathrm{MWT}$ and $P<0.003$ for secondary outcomes, following a Bonferroni correction.

Abbreviations: 6MWD, 6-minute walk test distance; CDSMP, Chronic Disease Self-Management Program; SF-36v2, Short Form 36 version 2.

\section{Discussion}

\section{Summary of results}

This is the first study to investigate the effect of the CDSMP itself on physical capacity in COPD, and whether limited supervised exercise produces additional benefit. This is important, because current formats of PR with an emphasis on lecture-style education and multiple weekly, health professional-supervised exercise sessions is costly, reaches only up to $50 \%$ of those to whom it is offered, ${ }^{3}$ and has waning effects over time. ${ }^{3}$ Wider-reaching, more costeffective and sustainable alternatives are needed.

We found a statistically significant mean increase in $6 \mathrm{MWD}$ for both groups, but no extra benefit for the supervised exercise component, apart from some evidence for an increase in the mean duration of moderate self-reported exercise by 1 hour in the intervention group. However, this probably reflected just what participants had received in the intervention itself. There was also an increase in "role physical" of the SF-36 for both groups, although this lost statistical significance following the Bonferroni adjustment.

\section{MWD}

Our study is the first on the CDSMP, when used for COPD self-management, to report in the literature a statistically significant increase in 6MWD for a self-management intervention alone (our control group). All participants in our study received a behaviorally-based educational and selfmanagement skills training intervention (CDSMP), in contrast to other studies where controls have typically been assigned to usual medical care ${ }^{7,8,20,21}$ or usual activities only. ${ }^{9}$

However, the mean increase in 6MWD achieved by both groups was small and might be regarded as of borderline clinical significance. Although the direction of change is consistent with an updated systematic review ${ }^{5}$ and other randomized controlled studies, ${ }^{8,9}$ it does not approach the previously reported MCID of $54 \mathrm{~m}\left(95 \%\right.$ confidence interval [CI] 37-71 m). ${ }^{32}$ 
Table 5 Change in outcomes: CDSMP + exercise versus CDSMP-only

\begin{tabular}{|c|c|c|c|c|c|c|c|c|c|}
\hline \multirow[t]{2}{*}{ Variable } & \multicolumn{3}{|c|}{ CDSMP + exercise (intervention) } & \multicolumn{3}{|c|}{ CDSMP-only (control) } & \multicolumn{3}{|l|}{ Change } \\
\hline & Baseline & Post & $P$-value & Baseline & Post & $P$-value & $\begin{array}{l}\text { CDSMP + } \\
\text { exercise }\end{array}$ & $\begin{array}{l}\text { CDSMP- } \\
\text { only }\end{array}$ & $P$-value \\
\hline 6MWD, m & $351.6 \pm 122.9$ & $370.2 \pm 128.2$ & 0.013 & $353.0 \pm 97.4$ & $373.0 \pm 97.7$ & 0.017 & $18.6 \pm 46.2$ & $20.0 \pm 50.6$ & 0.90 \\
\hline $\begin{array}{l}\text { Moderate exercise } \\
\text { duration, hours (pw) }\end{array}$ & $\begin{array}{l}0.50 \\
(0.0-19.5)\end{array}$ & $\begin{array}{l}1.75 \\
(0.0-30.8)\end{array}$ & 0.002 & $\begin{array}{l}1.50 \\
(0.0-10.3)\end{array}$ & $\begin{array}{l}1.38 \\
(0.0-15.8)\end{array}$ & 0.350 & $\begin{array}{l}1.00 \\
(-5.8-14.0)\end{array}$ & $\begin{array}{l}0.000 \\
(-9.8-10.3)\end{array}$ & 0.230 \\
\hline $\begin{array}{l}\text { Moderate exercise } \\
\text { frequency, times (pw) }\end{array}$ & $\begin{array}{l}2.0 \\
(0.0-20.0)\end{array}$ & $\begin{array}{l}3.0 \\
(0.0-22.0)\end{array}$ & 0.007 & $\begin{array}{l}2.0 \\
(0.0-23.0)\end{array}$ & $\begin{array}{l}3.0 \\
(0.0-22.0)\end{array}$ & 0.290 & $\begin{array}{l}1.0 \\
(-8.0-11.0)\end{array}$ & $\begin{array}{l}0.5 \\
(-23.0-16.0)\end{array}$ & 0.766 \\
\hline $\begin{array}{l}\text { Exercise self-efficacy, } \\
\text { scale } 0-5\end{array}$ & $2.7 \pm I .1$ & $2.9 \pm 1.1$ & 0.354 & $2.8 \pm 1.0$ & $3.0 \pm 1.0$ & 0.290 & $0.2 \pm 1.1$ & $0.2 \pm 1.1$ & 0.892 \\
\hline $\begin{array}{l}\text { Self-management } \\
\text { behaviors, scale 0-8 }\end{array}$ & $6.1 \pm 1.1$ & $6.3 \pm 0.8$ & 0.037 & $6.2 \pm 1.0$ & $6.4 \pm 1.0$ & 0.076 & $0.3 \pm 0.8$ & $0.2 \pm 0.7$ & 0.698 \\
\hline $\begin{array}{l}\text { Shortness of breath } \\
\text { severity, cm } \\
\text { Stage of change }\end{array}$ & $7.1 \pm 2.3$ & $6.3 \pm 2.5$ & 0.032 & $6.8 \pm 2.4$ & $6.8 \pm 2.3$ & 0.989 & $-0.8 \pm 2.4$ & $0.0 \pm 2.3$ & 0.118 \\
\hline Precontemplation & $4(10 \%)$ & $3(7 \%)$ & NS & $6(15 \%)$ & $4(10 \%)$ & NS & NS & NS & NS \\
\hline Contemplation & 14 (34\%) & $10(24 \%)$ & & 17 (43\%) & $13(33 \%)$ & & & & \\
\hline Preparation & $9(22 \%)$ & $4(10 \%)$ & & $7(18 \%)$ & $6(15 \%)$ & & & & \\
\hline Action & $6(15 \%)$ & $15(36 \%)$ & & $5(12 \%)$ & $9(22 \%)$ & & & & \\
\hline Maintenance & $8(19 \%)$ & $9(23 \%)$ & & $5(12 \%)$ & $8(20.0 \%)$ & & & & \\
\hline $\begin{array}{l}\text { Achieving weekly } \\
\text { exercise criteria: Yes }\end{array}$ & II (27\%) & $22(54 \%)$ & 0.066 & $6(15 \%)$ & $18(45 \%)$ & 0.013 & $19(47 \%)$ & $22(55 \%)$ & NS \\
\hline \multicolumn{10}{|l|}{ SF-36v2 domains below } \\
\hline Physical function & $29.3 \pm 9.0$ & $30.7 \pm 9.0$ & 0.076 & $29.0 \pm 8.0$ & $30.4 \pm 8.2$ & 0.254 & $1.5 \pm 5.2$ & $1.4 \pm 7.8$ & 0.963 \\
\hline Role physical & $32.0 \pm 10.4$ & $34.3 \pm 10.3$ & 0.033 & $32.1 \pm 9.4$ & $35.1 \pm 9.8$ & 0.038 & $2.4 \pm 6.9$ & $2.9 \pm 8.0$ & 0.752 \\
\hline Bodily pain & $45.6 \pm 11.7$ & $47.7 \pm 11.0$ & 0.206 & $45.1 \pm 11.5$ & $44.7 \pm 11.5$ & 0.621 & $2.1 \pm 10.3$ & $-0.6 \pm 7.9$ & 0.191 \\
\hline General health & $30.3 \pm 9.9$ & $31.2 \pm 8.6$ & 0.467 & $32.4 \pm 9.0$ & $31.8 \pm 10.1$ & 0.580 & $0.9 \pm 8.2$ & $-0.6 \pm 6.8$ & 0.361 \\
\hline Vitality & $41.7 \pm 9.2$ & $43.0 \pm 9.0$ & 0.382 & $40.8 \pm 9.7$ & $43.7 \pm 8.1$ & 0.032 & $1.2 \pm 8.8$ & $3.0 \pm 8.5$ & 0.366 \\
\hline Social function & $42.8 \pm 13.2$ & $43.3 \pm 10.9$ & 0.777 & $40.0 \pm 11.4$ & $43.2 \pm 11.1$ & 0.050 & $0.5 \pm 11.9$ & $3.8 \pm 10.2$ & 0.271 \\
\hline Role emotional & $36.3 \pm 16.1$ & $38.0 \pm 15.8$ & 0.282 & $37.2 \pm 15.3$ & $39.1 \pm 13.7$ & 0.358 & $1.7 \pm 10.0$ & $2.9 \pm 12.5$ & 0.956 \\
\hline Mental health & $47.7 \pm 11.7$ & $47.9 \pm 10.0$ & 0.849 & $46.2 \pm 10.7$ & $47.7 \pm 10.1$ & 0.428 & $0.2 \pm 6.4$ & $1.3 \pm 10.0$ & 0.567 \\
\hline $\begin{array}{l}\text { Physical component } \\
\text { summary }\end{array}$ & $31.5 \pm 8.2$ & $33.5 \pm 7.3$ & 0.026 & $32.0 \pm 7.2$ & $32.7 \pm 8.4$ & 0.506 & $2.0 \pm 5.6$ & $0.7 \pm 6.6$ & 0.340 \\
\hline $\begin{array}{l}\text { Mental component } \\
\text { summary }\end{array}$ & $46.7 \pm 12.9$ & $47.2 \pm 11.3$ & 0.707 & $45.5 \pm 12.2$ & $47.9 \pm 10.4$ & 0.205 & $0.4 \pm 7.1$ & $2.9 \pm 11.7$ & 0.362 \\
\hline
\end{tabular}

Notes: Data are reported as either raw number (percentage) within study group status, or as mean \pm standard deviation or median with range. The $P$-values are from Student's $t$-tests, Mann-Whitney U-tests or chi-squared analyses, with level of significance $P<0.05$ for the primary outcome and $P<0.003$ for the secondary outcomes, following a Bonferroni adjustment. $P$-values in bold are those which were below or approximated a $P$-value of 0.05 .

Abbreviations: 6MWD, 6-minute walk test distance; CDSMP, Chronic Disease Self-Management Program; NS, not significant as there were insufficient data to report significance; SF-36v2, Short Form 36 version 2; pw, per week.

On the other hand, our results do approach the more recently reported MCID of $25 \mathrm{~m}(95 \% \mathrm{CI} 20-61 \mathrm{~m}),{ }^{45}$ and others have also reported an MCID of $26 \pm 2 \mathrm{~m}$ in people with severe COPD following PR. ${ }^{46}$ Such small improvement may have particular relevance for severe COPD, and in our study, half of the participants were severely affected in this way. The 20 $\mathrm{m}$ change we observed is also within the lower limit of the CI observed by Holland et al. ${ }^{45}$

Other groups have also tried to reduce the PR frequency of weekly exercise component. These studies are relevant to our research, as we could offer only 1 weekly session of supervised exercise, in contrast to current recommendations. ${ }^{1,3}$ Thus, Singh et a $1^{9}$ compared twice-daily home-based walking recorded in a log and monitored once-weekly over 4 weeks with usual activities and found a significant increase in 6MWD for the intervention group but not the control group (54.2 $\pm 26.7 \mathrm{~m}$ versus $6.7 \pm 10.3 \mathrm{~m}, P<0.001)$. Finnerty et $\mathrm{al}^{8}$ compared education, plus once-weekly supervised exercise, plus an unsupervised home exercise program of 5 days per week over 6 weeks with usual care and reported a median increase in 6MWD of $51 \mathrm{~m}$ (range 20-81 m) in the intervention group. These studies contrast with the limited earlier evidence $\mathrm{e}^{7,47}$ on which the recommendation of at least twice-weekly supervised exercise sessions is based. Furthermore, no significant difference between once weekly or twice weekly exercisers for the incremental shuttle walking test was demonstrated in a recent randomized controlled trial. ${ }^{11}$ Others included a structured home exercise program to supervised 
exercise, also finding no additional benefit of two supervised sessions to the incremental shuttle walking test distance. ${ }^{10}$ These later studies of weekly versus twice-weekly supervised exercise point to uncertainty over the optimal frequency and mode of supervision required to increase physical capacity. They suggest that once-weekly exercise supervision with a structured home exercise program may be as good as more intensive regimes. To an extent, that is what we have tested, with negative results.

\section{Self-reported exercise}

In contrast with our study, others have reported a significant increase in self-reported exercise immediately following the CDSMP alone for people with chronic conditions, including COPD. ${ }^{48}$ One explanation could be that the measure of self-reported exercise we used is more comprehensive than the Stanford measure ${ }^{49}$ used previously. Thus, our study is the first CDSMP-related study to focus on COPD and the amount of moderate exercise which is required for optimal health benefits. ${ }^{35}$ Disappointingly, our results indicate that the CDSMP alone is of limited benefit for meeting the minimum recommendations of exercising in the community for 30 minutes on each of at least 5 days per week. Furthermore, the single supervised exercise session did not add anything in this regard either.

\section{Study limitations and implications for future research}

While a major strength of our study was its execution in "real world" clinical practice, utilizing existing resources, this also imposed some limitations. Firstly, due to ethical considerations, we were unable to include a second control group who did not receive any rehabilitation-type intervention. Secondly, it would have been informative to have a group in a twice-weekly or three-times-weekly supervised exercise schedule to determine whether this more exacting approach to exercise would add to the effects of the CDSMP. While this more intense exercise has its advocates, ${ }^{6}$ such an approach is highly resource-intensive; most other similar centers would have been unable to achieve this. Therefore, the effect of adding more than one supervised exercise session to the CDSMP is unknown, or indeed whether there are optimal numbers of weekly exercise sessions. This may be another area worthy of future research. However, even if more sessions are better, resource limitation will always be a major factor for generalizability within many health centers. Thirdly, participants were recruited from referrals to a hospital-based program that may differ from those who might self-refer to community-based CDSMPs. Nevertheless, our study reflects the usual practice for Australian PR, thus enhancing local generalizability. Fourthly, due to resource limitations, we were unable to offer separate sessions for CDSMP-exercise and CDSMP-only groups. While participants were requested not to discuss the exercise experience, vicarious "contamination" of the control group by the active intervention cannot be excluded. Fifthly, the leaders in this study were health professionals rather than peer leaders as is typical for other CDSMPs. Nevertheless, a recently published systematic review concluded that there were few differences between peer-led or health professional-led selfmanagement programs, ${ }^{27}$ suggesting this was unlikely to be a source of bias. Sixthly, we did not stratify randomization according to COPD severity. Although this did not vary a great deal, it may have yielded information as to a differential effect of the intervention and would be a consideration for future research. Finally, the CDSMP does not include a structured home exercise program, since under the license agreement, we were precluded from doing so.

\section{Conclusion}

In conclusion, participants with COPD attending a CDSMP can expect a small increase in their physical capacity, but there seems little point in adding a single supervised exercise session. Either there needs to be a more intensive conventional exercise program as advocated in guidelines, or new ways need to be investigated for successfully fostering adequate amounts of home or community-based exercise which meet current recommendations for optimizing health benefits. Before completely abandoning the CDSMP plus limited supervised exercise approach, we are currently undertaking such a trial using an additional community-based mentoring component.

\section{Acknowledgments}

This work was supported in part by the Australian Physiotherapy Association Beryl Haynes Memorial Fund Grant, Australia; the Royal Hobart Hospital Research Foundation Grant, Hobart, TAS, Australia, and a University of Tasmania Scholarship, Hobart, TAS, Australia. The authors would like to thank the Physiotherapy Department, Royal Hobart Hospital, Hobart, TAS, Australia where this research took place. We thank Associate Professor Leigh Blizzard, Menzies Research Institute Tasmania, University of Tasmania for his invaluable assistance with statistical analysis. Finally, we are indebted to the people with COPD who willingly gave of their time and of themselves to participate in our research. 


\section{Disclosure}

Helen L Cameron-Tucker received financial support for this research from the Australian Physiotherapy Association Beryl Haynes Memorial Fund Grant, Australia; the Royal Hobart Hospital Research Foundation Grant, Hobart, TAS, Australia, and a University of Tasmania Scholarship, Hobart, TAS, Australia. There are no other potential conflicts of interest pertaining to this work.

\section{References}

1. Bolton CE, Bevan-Smith EF, Blakey JD, et al. British Thoracic Society guideline on pulmonary rehabilitation in adults. Thorax. 2013; 68(Suppl 2):ii1-ii30.

2. Ries AL, Bauldoff GS, Carlin BW, et al. Pulmonary rehabilitation: joint ACCP/AACVPR evidence-based clinical practice guidelines. Chest. 2007;131(Suppl 5):4S-42S.

3. Spruit MA, Singh SJ, Garvey C, et al. An official American Thoracic Society/European Respiratory Society statement: key concepts and advances in pulmonary rehabilitation. Am J Respir Crit Care Med. 2013;188(8):e13-e64.

4. Global Strategy for the Diagnosis MaPoC, Global Initiative for Chronic Obstructive Lung Disease (GOLD). 2013. Available from: http://www. goldcopd.org/. Accessed June 21, 2013.

5. Lacasse Y, Goldstein R, Lasserson TJ, Martin S. Pulmonary rehabilitation for chronic obstructive pulmonary disease. Cochrane Database Syst Rev. 2006;(4):CD003793.

6. Nici L, Donner C, Wouters E, Zuwallack Z, et al. American Thoracic Society/European Respiratory Society statement on pulmonary rehabilitation. Am J Respir Crit Care Med. 2006;173(12):1390.

7. Ringbaek T, Broendum E, Hemmingsen L, et al. Rehabilitation of patients with chronic obstructive pulmonary disease. Exercise twice a week is not sufficient! Respir Med. 2000;94(2):150-154.

8. Finnerty J, Keeping I, Bullough I, Jones J. The effectiveness of outpatient pulmonary rehabilitation in chronic lung disease: a randomized controlled trial. Chest. 2001;119(6):1705-1710.

9. Singh V, Khandelwal DC, Khandelwal R, Abusaria S. Pulmonary rehabilitation in patients with chronic obstructive pulmonary disease. Indian J Chest Dis Allied Sci. 2003;45(1):13-17.

10. Liddell F, Webber J. Pulmonary rehabilitation for chronic obstructive pulmonary disease: a pilot study evaluating a once-weekly versus twice-weekly supervised programme. Physiotherapy. 2010;96(1):68-74.

11. O’Neill B, McKevitt A, Rafferty S, et al. A Comparison of twice- versus once-weekly supervision during pulmonary rehabilitation in chronic obstructive pulmonary disease. Arch Phys Med Rehabil. 2007;88(2): 167-172.

12. HyunSoo O, WhaSook S. Meta-analysis of the effects of respiratory rehabilitation programmes on exercise capacity in accordance with programme characteristics. J Clin Nurs. 2006;16:3-5.

13. Blackstock F, Webster K. Disease-specific health education for COPD: a systematic review of changes in health outcomes. Health Educ Res. 2007;22(5):703-717.

14. Blackstock FC, Webster KE, McDonald CF, Hill CJ. Comparable improvements achieved in chronic obstructive pulmonary disease through pulmonary rehabilitation with and without a structured educational intervention: a randomized controlled trial. Respirology. Epub November 21, 2013.

15. Griffiths T1, Burr ML, Campbell IA, et al. Results at 1 year of outpatient multidisciplinary pulmonary rehabilitation: a randomised controlled trial. Lancet. 2000;355(9201):362-368. Erratum in: Lancet. 2000;355(9211):1280. Lonescu AA [corrected to Ionescu AA].

16. Ries AL, Kaplan RM, Limberg TM, Prewitt LM. Effects of pulmonary rehabilitation on physiologic and psychosocial outcomes in patients with chronic obstructive pulmonary disease. Ann Intern Med. 1995;122(11): $823-832$.
17. Clark NM, Becker MH, Lorig K, Rakowski W, Anderson L. SelfManagement of chronic disease by older adults. J Aging Health. 1991; $3(1): 3-27$

18. Corbin S, Strauss J. Unending Work and Care: Managing Chronic Illness at Home. San Francisco, CA: Jossey-Bass; 1988.

19. Walters JA, Turnock AC, Walters EH, Wood-Baker R. Action plans with limited patient education only for exacerbations of chronic obstructive pulmonary disease. Cochrane Database Syst Rev. 2010(5): CD005074.

20. Bourbeau J, Julien M, Maltais F, et al. Reduction of hospital utilization in patients with chronic obstructive pulmonary disease: a disease-specific self-management intervention. Arch Intern Med. 2003;163(5):585.

21. Monninkhof E, van der Valk P, van der Palen J, van Herwaarden C, Zielhuis G. Effects of a comprehensive self-management programme in patients with chronic obstructive pulmonary disease. Eur Respir J. 2003;22(5):815-820.

22. Cosgrove D, MacMahon J, Bourbeau J, Bradley J, O’Neill B. Facilitating education in pulmonary rehabilitation using the Living Well with COPD programme for pulmonary rehabilitation: a process evaluation. BMC Pulm Med. 2013;13(1):50.

23. Apps LD, Mitchell KE, Harrison SL, et al. The development and pilot testing of the Self-management Programme of Activity, Coping and Education for Chronic Obstructive Pulmonary Disease (SPACE for COPD). Int J COPD. 2013;8:317-327.

24. Taylor SJC, Sohanpal R, Bremner SA, et al. Self-management support for moderate-to-severe chronic obstructive pulmonary disease: a pilot randomised controlled trial. Br J Gen Pract. 2012:e687-e695.

25. Effing T, Monninkhof Evelyn EM, van der Valk Paul PDLPM, et al. Self-management education for patients with chronic obstructive pulmonary disease. Cochrane Database Syst Rev. 2007(4): CD002990.

26. Lorig KR, Sobel DS, Stewart AL, et al. Evidence suggesting that a chronic disease self-management program can improve health status while reducing hospitalization: a randomized trial. Med Care. 1999;37(1):5-14.

27. Foster G, Taylor Stephanie JC, Eldridge S, Ramsay J, Griffiths Chris J. Self-management education programmes by lay leaders for people with chronic conditions. Cochrane Database Syst Rev. 2007(4): CD005108.

28. Bandura A. Social Foundations of Thought and Action: A Social Cognitive Theory. Englewood Cliffs, NJ: Prentice Hall; 1986.

29. Lorig K, Sobel DS, Ritter PL, Laurent D, Hobbs M. Effect of a self-management program on patients with chronic disease. Eff Clin Pract. 2001;4(6):256-262.

30. Cameron-Tucker HL, Wood-Baker R. COPD, Rehabilitation and the Stanford Chronic Disease Self- Management Programme (poster P-122). Respirology. 2006;11(s5):A159. http://www.blackwell-synergy. com/doi/abs/10.1111/j.1440-1843.2006.00997.x. Accessed February 3, 2008.

31. Guyatt G, Thompson PJ, Berman BM, et al. How should we measure function in patients with chronic heart and lung disease? J Chron Dis. 1985;38:517-524

32. Redelmeier DA, Bayoumi AM, Goldstein RS, Guyatt GH. Interpreting small differences in functional status: the Six Minute Walk test in chronic lung disease patients. Am J Respir Crit Care Med. 1997;155(4): 1278-1282.

33. Balady GJ. American College of Sports Medicine, ACSM's Guidelines for Exercise Testing and Prescription. 6th ed. Philadelphia, London: Lipponcott Williams and Wilkins; 2000.

34. Borg GAV. Psychological bases of physical exertion. Medicine and Science in Sports and Exercise. 1982;14:377-381.

35. Australian Institute of Health and Welfare. The Active Australia Survey: a guide and manual for implementation, analysis and reporting. 2003. Available from: http://www.aihw.gov.au/publications/cvd/aas/aas.pdf. Accessed 20 April, 2004.

36. Cancer Prevention Research Center [homepage on the Internet]. Exercise: stages of change - short form. 1991. Available from: http:// www.uri.edu/research/cprc/Measures/Exercise02.htm. Accessed September 20, 2004. 
37. Cancer Prevention Research Center. Exercise: self-efficacy measure. 1991. Available from: http://www.uri.edu/research/cprc/Measures/ Exercise04.htm. Accessed September 20, 2004.

38. Gift AG. Validation of a vertical visual analogue scale as a measure of clinical dyspnea. Rehabil Nurs. 1989;14(6):323-325.

39. Stewart A, Mills KM, King AC, Haskell WL, Gillis D, Ritter PL. CHAMPS physical activity questionnaire for older adults. Med $\mathrm{Sci}$ Sports Exerc. 2001;33(7):1126-1141.

40. Battersby M, Ask A, Reece M, Marwick M. The Partners in Health scale: the development and psychometric properties of a generic assessment scale for chronic condition self-management. Aust J Prim Health. 2003;9(2/3):41-49.

41. Ware JE, Kosinski M, Dewey JE. How to Score Version 2 of the SF-36 Health Survey. Lincoln, RI: Quality Metric Incorporated; 2000.

42. Jones PW. St George's Respiratory Questionnaire: MCID. COPD. 2005;2(1):75-79.

43. Jones PW, Kaplan RM. Methodological issues in evaluating measures of health as outcomes for COPD. Eur Respir J. 2003; 21(Suppl 41):13S-18S.

44. Pallant J. SPSS Survival Manual. 2nd ed. Crows Nest: Allan and Unwin; 2005.
45. Holland A, Hill C, Rasekaba T, Lee A, Naughton M, McDonald C. Updating the minimal important difference for six-minute walk distance in patients with chronic obstructive pulmonary disease. Arch Phys Med Rehabil. 2010;91(2):221-225.

46. Puhan MA, Chandra D, MosenifarZ, et al. The minimal important difference of exercise tests in severe COPD. Eur Respir J. 2011;37(4):784-790.

47. Puente-Maestu L, Sanz M, Sanz P, Cubillo J, Mayol J, Casaburi R. Comparison of effects of supervised versus self-monitored training programmes in patients with chronic obstructive pulmonary disease. Eur Respir J. 2000;15(3):517-525.

48. Siu AM, Chan CC, Poon PK, Chui DY, Chan SC. Evaluation of the chronic disease self-management program in a Chinese population. Patient Educ Couns. 2007;65(1):42-50.

49. Lorig K, Stewart A, Ritter P, Gonzalez V, Laurent D, Lynch J. Outcome Measures for Health Education and Other Interventions. Thousand Oaks, CA: Sage Publications, Inc.; 1996.

50. Abramson M, Crockett AJ, Dabscheck E, et al on behalf of Lung Foundation Australia and the Thoracic Society of Australia and New Zealand. The COPD-X Plan: Australian and New Zealand Guidelines for the management of Chronic Obstructive Pulmonary Disease. V2.35, 2013 Available from: http://www.copdx.org.au/. Accessed August 19, 2013.
International Journal of COPD

\section{Publish your work in this journal}

The International Journal of COPD is an international, peer-reviewed journal of therapeutics and pharmacology focusing on concise rapid reporting of clinical studies and reviews in COPD. Special focus is given to the pathophysiological processes underlying the disease, intervention programs, patient focused education, and self management protocols.

\section{Dovepress}

This journal is indexed on PubMed Central, MedLine and CAS. The manuscript management system is completely online and includes a very quick and fair peer-review system, which is all easy to use. Visit http://www.dovepress.com/testimonials.php to read real quotes from published authors. 